\title{
INGLÊS PARA FINS ACADÊMICOS E O ENSINO A DISTÂNCIA: PONTOS DE CONTATO E PROBLEMÁTICAS
}

\author{
INGLÉS PARA FINES ACADÉMICOS Y EL APRENDIZAJE A DISTANCIA: PUNTOS \\ DE CONTACTO Y PROBLEMAS
}

\author{
ENGLISH FOR ACADEMIC PURPOSES AND E-LEARNING: POINTS OF \\ CONSISTENCY AND ISSUES
}

\author{
Ana Helena DOTTI CAMPANATTI ${ }^{1}$ \\ Tamiris Destro COSTA ${ }^{2}$ \\ Sandra Mari KANEKO-MARQUES ${ }^{3}$
}

RESUMO: O objetivo deste artigo é tecer algumas considerações e reflexões a respeito do senso de plausibilidade do professor, especificamente para fins acadêmicos, num contexto de aulas em ambiente online síncrono. Para tanto, primeiramente discorreremos acerca do conceito do senso de plausibilidade. Em segundo lugar, abordaremos a temática do ensino e aprendizagem de línguas que utilizam ferramentas e/ou plataformas online, bem como a definição do conceito de EAD (ensino a distância), além de discutir a respeito da definição da noção de IFA (Inglês para Fins Acadêmicos). Posteriormente, focalizaremos questões envolvendo relatos de experiências de cursos de IFA em ambiente EAD. E por fim, faremos considerações com vistas a apontar possíveis problemáticas e encaminhamentos no que diz respeito à abordagem do ensino de inglês para fins acadêmicos em contextos EAD

PALAVRAS-CHAVE: Ensino de língua inglesa. Inglês para fins acadêmicos. Ensino a distância.

RESUMEN: El propósito de este artículo es hacer algunas consideraciones y reflexiones sobre el sentido de plausibilidad del profesor especificamente para fines académicos en el contexto de la educación a distancia sincrona. Para esto, primeiro discutiremos el concepto del sentido de plausibilidad. En segundo momento, tendremos el foco en la enseñanza y el aprendizaje de idiomas utilizando herramientas y plataformas de educación a distancia, así como definiendo el concepto de aprendizaje a distancia (ODL), así como discutiendo la definición de la noción de IFA (inglés para fines academicos). Tercero, nos enfocaremos más especificamente em temas que involucran informes de experiencia de cursos de IFA en el entorno de ODL. Finalmente, haremos consideraciones con el fin de señalar posibles problemas y referencias sobre el enfoque de la enseñanza del inglés con fines académicos en contextos $O D L$.

${ }^{1}$ Universidade Estadual Paulista (UNESP), Araraquara - SP - Brasil. Mestranda no Programa de Pós-Graduação em Linguística e Língua Portuguesa. ORCID: http://orcid.org/0000-0001-7496-197X. E-mail: anacampanatti@gmail.com

${ }^{2}$ Universidade Estadual Paulista (UNESP), Araraquara - SP - Brasil. Doutoranda no Programa de Pós-Graduação em Linguística e Língua Portuguesa. Bolsista CNPq. ORCID: https://orcid.org/0000-0003-1102-4385. E-mail: ta.dc@hotmail.com

${ }^{3}$ Universidade Estadual Paulista (UNESP), Araraquara - SP - Brasil. Docente no Departamento de Letras Modernas. Doutorado em Estudos Linguísticos (UNESP). ORCID: http://orcid.org/0000-0002-4755-5375. Email: sandra.kaneko@unesp.br 
PALABRAS CLAVE: Enseñanza del idioma inglês. Inglês para fines académicos. la educación a distancia.

ABSTRACT: This article aims to consider and reflect upon the teacher's sense of plausibility, specifically for Academic Purposes, within the context of online classes. For this, we will examine some aspects of the concept of the teacher's sense of plausibility. as well as the concept of distance learning (DL) and, likewise, the definition of EAP's (English for Academic Purposes). Secondly, we will concentrate, specifically, on questions involving experience reports on Distance EAP courses. Finally, we will make considerations as to point out problems and possible outcomes to EAP approaches in Distance learning contexts.

KEYWORDS: English language teaching. English for academic purposes. Distance learning.

\section{Introdução}

Ao ensinar uma língua estrangeira (LE), é comum que o professor se depare com diversas questões ao refletir sobre o planejamento de seu curso, tais com o método e a abordagem $^{4}$ de ensino mais adequados a serem adotados em sua sala de aula, bem como o material a ser utilizado. Prabhu (1990) aponta a noção do "senso de plausibilidade" como um conceito que envolveria a concepção de língua do professor, seus conhecimentos e objetivos no desenvolvimento de suas aulas. Assim, por meio de seu senso de plausibilidade, o professor seria capaz de refletir sobre a abordagem mais apropriada para utilizar em sala de aula e de que maneira poderia planejá-la e aplicá-la.

É válido mencionar que o senso de plausibilidade está intrinsecamente relacionado às expectativas do professor e de seus alunos, de modo que seja significativo e produtivo aos alunos para que possam refletir sobre seu aprendizado, além disso o foco do senso de plausibilidade do professor está no processo de aprender e não somente no produto. Ademais, o autor salienta que o senso de plausibilidade deve ser "mantido vivo e aberto a mudanças, não pode se tornar mecânico", e também pode ser partilhado e compartilhado com outros professores.

De maneira mais específica, ao tratarmos da língua inglesa, que é o foco de nosso estudo, sabemos que se trata de uma língua internacional, que é utilizada em ambientes variados, seja na vida profissional, acadêmica ou por entretenimento. Com o advento das novas tecnologias e a internet, o domínio do inglês tornou-se cada vez mais necessário em nosso cotidiano, além

${ }^{4}$ Para as distinções entre método e abordagem, c.f. artigos Prabhu (1978); (1990); (2001). 
disso as novas tecnologias também proporcionam múltiplas formas de ensino e aprendizagem de línguas estrangeiras.

Diante disso, há que se pensar em duas questões específicas: na atualização dos professores quanto à importância do senso de plausibilidade no contexto de ensino e aprendizagem de LE por um lado e, por outro, na inclusão das novas tecnologias e internet no ensino com vistas a atender os diferentes perfis e necessidades dos aprendizes. Assim sendo, este artigo tem por objetivo tecer considerações e reflexões a respeito do senso de plausibilidade do professor no ensino de inglês, especificamente para fins acadêmicos num contexto de aulas em ambiente online síncrono.

Neste sentido, defendemos que, para que o ensino de línguas estrangeiras, especificamente de inglês, em sala de aula ocorra com êxito, o professor deve conhecer alguns conceitos pertinentes ao tema sobre os métodos e abordagens de LE, para que possa compreender de forma mais específica a questão do senso de plausibilidade.

Ainda podemos mencionar a premência da compreensão das necessidades e objetivos do aluno, para entender as dificuldades que este apresenta, seu perfil e visão de mundo, por isso, faremos, na próxima seção considerações sobre os principais fatores que permeiam a importância da noção do senso de plausibilidade do professor em sala de aula.

Portanto, a seguir, discutiremos, de maneira mais detalhada, os assuntos abordados aqui brevemente e também buscaremos mostrar pontos de contato entre o senso de plausibilidade do professor e as noções de inglês para fins acadêmicos (IFA), além de situar essas questões em ambientes mediados pela tecnologia.

\section{O senso de plausibilidade do professor e o desafio perante as novas tecnologias}

Tendo em mente a importância do senso de plausibilidade do professor no ensino de LE, faremos algumas observações acerca do conceito de método e o momento em que estamos inseridos. De acordo com Leffa (2012), atualmente vivemos na era pós-método. Primeiramente proposta por Kumaravadivelu (2003, p. 33, tradução nossa):

[...] a condição pós-método capacita os profissionais a construir teorias pessoais de prática. [...] [Ele] permite que tais profissionais criem estratégias inovadoras orientadas para a sala de aula e especificidades locais. [...] A condição pós-método $[. .$.$] reconhece o potencial dos professores de saber não$ somente como ensinar, mas também como agir de maneira autônoma dentro dos limites acadêmicos e administrativos impostos pelas instituições, currículo e livros didáticos. Além disso, tal condição também promove a capacidade dos professores de saber como desenvolver uma abordagem crítica 
de modo a observar, analisar e avaliar as suas próprias práticas de ensino, a fim de alcançar as mudanças desejadas. ${ }^{5}$

Assim sendo, a escolha das abordagens, técnicas e atividades utilizadas ao longo das aulas devem estar em consonância com o contexto do estudante, de modo que a aula seja significativa e de certa forma mais facilitada ao olhar do aprendiz, por isso trataremos de alguns princípios pertencentes às novas tecnologias que podem auxiliar na reflexão e no trabalho do professor, bem como no desenvolvimento de conhecimentos, interação e autonomia dos aprendizes em ambiente escolar, visto que, atualmente, o contato com computadores, smartphones e internet, por exemplo, é mais facilitado, sendo que os alunos, expostos a tais tecnologias em suas práticas sociais, muitas vezes aprendem e interagem de maneiras diferentes das abordadas em sala de aula. Por isso, é necessário que o professor considere o uso das novas tecnologias como um meio de aproximação e interação entre a realidade do aluno e a prática em contexto escolar.

As novas tecnologias têm modificado várias atividades da vida moderna, inclusive o ensino e a aprendizagem de línguas. Nesse sentido, há que se pensar em como podemos "letrar digitalmente uma nova geração de aprendizes que estão crescendo e vivenciando os avanços da tecnologia de informação e comunicação" (XAVIER, 2002, p. 1).

Além disso, é necessário refletir sobre a questão dos imigrantes e nativos digitais e o modo como estes pensam e processam informações de maneira diferente. Prensky (2001), adota o termo "sotaque", que estaria relacionado à adaptação do imigrante digital em novos contextos, ou seja, como este imigrante recorre ao seu passado, às suas raízes, ao que estava acostumado, para se fazer "inteligível" ou de certa forma lidar com o novo que lhe foi imposto. Podemos destacar a necessidade de imprimir um e-mail como um exemplo de "sotaque".

Hoje em dia, os nossos alunos são todos "falantes nativos" da língua digital dos computadores, videogames e da internet. Então, o que fazer com o resto de nós? Aqueles que não nasceram na era digital, mas que, em determinado momento de suas vidas, tornaram-se fascinados e adotaram muitos ou a maioria dos aspectos da nova tecnologia são e sempre serão comparados com eles, Imigrantes Digitais (PRENSKY, 2001, p. 2; grifos do autor, tradução nossa). ${ }^{6}$

${ }^{5}$ No original: "[...] the postmethod condition empowers practitioners to construct personal theories of practice. [...] [It] enables practitioners to generate location-specific, classroom-oriented innovative strategies. [...] The postmethod condition [...] recognizes the teachers' potential to know not only how to teach but also how to act autonomously within the academic and administrative constraints imposed by institutions, curricula, and textbooks. It also promotes the ability of teachers to know how to develop a critical approach in order to selfobserve, self-analyze, and self-evaluate their own teaching practice with a view to effecting desired changes." (p. 33)

${ }^{6}$ No original: “Our students today are all 'native speakers' of the digital language of computers, video games and the Internet. So what does that make the rest of us? Those of us who were not born into the digital world but have, 
Portanto, Prensky (2001) destaca que é necessário refletir sobre a necessidade de mudarmos a nossa forma de ensinar, ajustando-a aos novos contextos sociais e tecnológicos que nossos alunos se inserem, pois muitas vezes não temos os subsídios, competência e capacitação necessárias para acompanhar a evolução de nossos aprendizes na era digital.

Concernente a tal fato, Pessôa e Duqueviz (2012) destacam o documento "Padrões de competência em TIC para professores", da UNESCO (2009), que aponta o uso eficiente da tecnologia por parte tanto dos professores quanto dos alunos, com vistas a possibilitar que os aprendizes se tornem:

usuários qualificados das tecnologias da informação; pessoas que buscam, analisam e avaliam a informação; solucionadores de problemas e tomadores de decisões; usuários criativos e efetivos de ferramentas de produtividade; comunicadores, colaboradores, editores e produtores; cidadãos informados, responsáveis e que oferecem contribuições (UNESCO, 2009, apud PESSÔA; DUQUEVIZ, 2012, p. 5).

Além disso, Cuban (2015, apud DUQUEVIZ, 2017, p. 25) e Cysneiros (1999, apud DUQUEVIZ, 2017, p. 25) nos apresentam críticas à presença das novas tecnologias em ambiente escolar e "avaliam as TDIC como uma promessa de mudança na educação que não se cumpriu”, já Viana (2015 apud DUQUEVIZ, 2017) acredita que as TDICs (Tecnologias Digitais de Informação e Comunicação) podem “impulsionar” uma mudança na educação, com o foco "no protagonismo dos alunos", de modo que se faz cada vez mais necessária a capacitação de professores acerca do uso das TDICs em sala de aula, para que possam estar atualizados com os recursos e ferramentas proporcionados pelas novas tecnologias e consigam fazer um bom uso das mesmas.

Neste sentido, acreditamos que a tecnologia deve ser pensada e incluída em sala de aula de maneira significativa e não somente para preencher lacunas. É verdade que tal tarefa não é um trabalho fácil para professores que foram expostos a outros tipos de contextos em sua educação, entretanto, é necessário que este professor reflita sobre os métodos, abordagens e técnicas que serão mais significativas para seus estudantes, ou seja, o modo como aprendíamos muitas coisas no passado deve ser atualizado/adaptado/redefinido para ter sentido no atual mundo digital.

Portanto, é necessário que o professor esteja atento ao seu público-alvo, suas necessidades, o currículo, os objetivos e todas as questões teóricas que perpassam a sua concepção de língua e abordagem de ensino: tais questões estão associadas ao senso de

at some later point in our lives, become fascinated by and adopted many or most aspects of the new technology are, and always will be compared to them, Digital Immigrants." 
plausibilidade do professor, que deve estar sempre aberto às novas mudanças e em consonância com a teoria e a prática utilizada em sala de aula.

Assim sendo, na próxima seção deste artigo, abordaremos questões sobre o ensino de línguas para fins acadêmicos, especificamente o EAP (English for Academic Purposes), em concordância com o uso das TDICs (Tecnologias Digitais de Informação e Comunicação), com enfoque em questões do ensino em ambiente online.

\section{O ensino de inglês para fins acadêmicos em ambiente online}

No contexto de ensino e aprendizagem de línguas, a motivação dos aprendizes é fundamental, e há diversos fatores que podem motivar esse aluno (aspectos pessoais, socioculturais e contextuais). Segundo o dicionário Michaelis (2009), a palavra motivação pode ser definida como uma "espécie de energia psicológica ou tensão que põe em movimento o organismo humano, determinando um dado comportamento".

Dentro de uma abordagem tradicional (psicológico-social) sobre motivação na área de LE, Gardner e Lambert (1959 apud CAMPOS-GONELLA, 2007), a definem como inerente à orientação do aprendiz ao objetivo de aprender uma língua estrangeira.

Nesse sentido, os autores fazem distinção entre motivação integrativa e motivação instrumental, motivação integrativa associada a atitudes positivas vinculadas ao grupo que fala a língua-alvo, sua cultura, seus costumes e suas tradições, enquanto a motivação instrumental diz respeito às razões mais práticas de se aprender uma língua, como o aumento das chances de conseguir um bom emprego, uma promoção, passar num exame ou entrar em uma universidade estrangeira, entre outros fatores.

Desse modo, Witter e Lomônaco (1984 apud DA SILVA; ESTARNECK, 2010) contribuem com a definição entre a motivação intrínseca e extrínseca.

[...] aquela em que a atividade surge como decorrência da própria aprendizagem, o material estudado fornece o próprio reforço, a tarefa é feita porque é agradável. Já a motivação extrínseca ocorre quando a aprendizagem é concretizada para atender a um outro propósito, como por exemplo passar no exame, subir socialmente (p. 67).

Assim, entendemos que a motivação pode influenciar o processo de ensino e aprendizagem, segundo os propósitos do aprendizado. O que, de fato, é de extrema relevância e recai sobre o quão significativo deve ser o ensino do aprendiz, ou seja, o aluno deve ver sentido e aplicabilidade no que se aprende, para que se sinta motivado, despertando o seu interesse em atingir seus objetivos no aprendizado da língua-alvo. Portanto, podemos pensar 
em um ensino que também considere as necessidades desse aprendiz, além de refletirmos acerca de tecnologias que facilitem sua aprendizagem.

Diante de tal cenário, faremos algumas considerações sobre o contexto de IG (Inglês Geral) e IFA com vistas a compreendê-los de maneira mais detalhada.

No contexto de Inglês Geral (IG), o foco de ensino está ligado às quatro habilidades linguísticas: compreensão e produção escrita e compreensão e produção oral (reading, writing, listening and speaking) (LARSEN-FREEMAN, 2013). Normalmente os aspectos gramaticais e funcionais são aspectos norteadores para organização das aulas, materiais e métodos de avaliação: por exemplo, em livros didáticos, geralmente, são apresentados os verbos no presente para que depois sejam estudadas as formas verbais no passado. O propósito maior seria atingir a proficiência e fluência necessárias para êxito nas interações comunicativas do cotidiano.

Já no contexto de Inglês para Fins Acadêmicos (IFA), o foco está no aluno (HUTCHINSON; WATERS, 1987) e em seu(s) objetivo(s) com determinado curso, diferentemente do Inglês Geral, a área de conhecimento do aluno é a base para desenvolver habilidades linguísticas e competências específicas, é por meio de assuntos já conhecidos pelos alunos e presentes em sua vida acadêmica que serão desenvolvidas as habilidades linguísticas e as competências necessárias com vistas a melhorar seu desempenho em diferentes situações acadêmicas (DE CHAZAL, 2014).

Dessa forma, normalmente observamos a parceria entre aluno e professor, pois o aluno contribui com seu conhecimento técnico sobre o assunto e o professor com seus conhecimentos linguísticos, assim, "o papel do professor vai depender do tipo de curso e de seu conteúdo" (JORDAN, 1997 apud VIAN JR. 2015 p. 191).

Logo, o material utilizado nesse contexto normalmente apresenta textos, dissertações, artigos, seminários e apresentações que são comuns ao contexto e a cultura acadêmica do aprendiz (DUDLEY-EVANS, 1987), com o intuito de auxiliá-lo em sua compreensão e produção escrita e/ou oral na língua-alvo.

Para tanto, é importante a realização de atividades que reflitam as necessidades dos aprendizes, pois, dessa maneira o professor terá um ponto de partida para o planejamento e seleção de materiais e atividades, além de ter mais informações para planejar o nivelamento, sequenciamento da língua e conteúdos num contexto de IFA.

Neste sentido, baseamo-nos em Jordan (1997, p. 57) com o intuito de apresentar uma síntese para o planejamento de cursos em contextos de IFA, sendo esta fundamentada em: a) Análise de necessidades - de alunos (para informações como perfil e nível de proficiência, por exemplo), do assunto ou departamento (dados como gênero textual, cultura acadêmica, etc.); b) 
Objetivos - dos estudantes e do curso em si; c) Recursos e Materiais - com variáveis e possíveis restrições; d) Tipo de ementa ou plano de ensino - conteúdo e componentes, habilidades linguísticas e horários; e) Metodologia (organização de ensino/aprendizagem) - individual, em grupo e também os materiais a serem utilizados, e, por fim, f) Avaliação e fedback, com vistas a analisar o desempenho linguístico do aluno dentro do que se espera dele no contexto acadêmico.

Assim sendo, o professor de cursos de IFA, por meio da análise das necessidades dos aprendizes saberá sobre as principais motivações (que podem ser dada pelo propósito do curso em si, como desenvolver habilidades para realizar um exame de proficiência, ou por outros motivos pessoais, profissionais, etc.) e objetivos de seu aluno, seus quereres, que podem até não coincidir com o que realmente precisam aprender em um determinado curso; além disso, o professor poderá entender melhor as dificuldades de seus alunos e o que esperar deles, considerando o conhecimento prévio, bem como o nível de proficiência e estratégias de aprendizagem desses estudantes.

Tal análise também pode ser realizada em forma de questionários, entrevistas, observações em sala de aula, provas, trabalhos, estudos de caso, auto avaliação, pré e pós testes, diários reflexivos, etc. Entretanto, há algumas limitações nas análises de necessidades que precisam ser consideradas, dentre elas podemos citar a dificuldade em atender as necessidades dos alunos diante de uma classe heterogênea, principalmente com níveis de proficiência bem diferentes, ou mesmo com diferentes necessidades e objetivos; além disso, o tempo disponível para realização do curso pode interferir na aplicação de atividades para avaliar as necessidades dos aprendizes, uma vez que tais atividades consomem uma parcela considerável de tempo durante as aulas.

Também vemos a análise de necessidades como limitação quando consideramos apenas as necessidades-alvo do aprendiz, excluindo outras fontes: é neste sentido que o professor deve ter senso de plausibilidade para nortear e avaliar o que pode ser válido e proveitoso nas etapas de planejamento e elaboração de materiais.

Nesta perspectiva, consideramos que o senso de plausibilidade do professor aliado ao uso da análise das necessidades dos aprendizes, bem como a motivação destes (interesses pessoais, profissionais e acadêmicos, por exemplo) e seus objetivos são de extrema importância para a elaboração de cursos em contextos de IFA.

Atrelado a essas questões e diante do cenário atual, com o advento das novas tecnologias, especialmente a partir da década de 2010, “o ensino de línguas vem se modificando 
com a evolução dos recursos tecnológicos" e a tecnologia tem se mostrado como um meio de “superar barreiras físicas e temporais” (SILVA; SHITSUKA; MORAIS, 2013, p. 11).

Ao nos referirmos ao ensino de línguas em ambiente online, é necessário fazer alguns apontamentos sobre conceitos como EAD (educação a distância), e e-learning a fim de elucidar questões proeminentes ao ensino online.

Mill (2018) destaca o EAD como "modalidade de educação" e "um modo específico de organizar o ensino-aprendizagem". O autor também pontua que "a EAD é uma modalidade que apresenta como característica essencial a proposta de ensinar e aprender, sem que os professores e alunos precisem estar no mesmo local ao mesmo tempo" (MILL, 2018, p. 200). Ademais, a modalidade EAD deve ser pensada como algo que surge das necessidades e objetivos dos alunos, tratando-se de um processo planejado e não acidental de aprendizado, de modo a incluir as novas tecnologias, envolvendo o aluno no processo de aprendizagem de maneira significativa e acessível.

Quanto ao contexto de e-learning, Gomes (2005) destaca que esse envolve "um cenário de ensino a distância baseado na comunicação e na colaboração", ainda de acordo com Gomes (2005) "a clarificação de conceitos como "educação a distância" ou "e-learning" não é tarefa fácil, de modo geral, podemos dizer que o e-learning perpassa praticamente todas as modalidades de ensino, sendo uma das possíveis configurações da EAD, mas não podendo ser considerado como sinônimo de EAD.

[...] o e-learning, do ponto de vista tecnológico está associado, e tem como suporte, a Internet e os serviços de publicação de informação e de comunicação que esta disponibiliza, e do ponto de vista pedagógico implica a existência de um modelo de interação entre professor-aluno (formadorformando), a que, em certas abordagens, acresce um modelo de interação aluno-aluno (formando-formando), numa perspectiva colaborativa.

$\mathrm{O}$ e-Learning, enquanto modalidade de formação a distância e em algumas situações de formação em regime misto (b-learning) implica também a disponibilização de materiais (referentes aos conteúdos de ensino, frequentemente referidos por e-conteúdos) especificamente construídos para estes ambientes de aprendizagem (GOMES, 2005, p. 234).

Contudo, algumas questões devem ser consideradas ao se tratar dessas novas possibilidades. Tendo em vista o contato prévio com a escola regular e modelos mais tradicionais de ensino, nos indagamos se esse aluno estaria preparado para trabalhar de maneira ativa e com mais autonomia dentro desse cenário. Da mesma forma, refletimos acerca das habilidades e capacitação desse professor para nortear e atuar em tal cenário. 
Tendo em vista as ponderações citadas anteriormente, apontamos a necessidade de constante reflexão por parte dos professores no que diz respeito às necessidades de seus alunos, bem como aos novos contextos que estão inseridos.

Portanto, na seção seguinte, abordaremos o contexto de um curso de Inglês para Fins Acadêmicos em ambiente online, com vistas a elucidar a nossa prática relacionada às questões teóricas tratadas anteriormente.

\section{Da teoria à prática: um curso EAD de IFA}

A fim de ilustrar as discussões teóricas dos itens anteriores, abordaremos, neste quarto tópico, um curso ministrado por uma das autoras deste artigo durante o primeiro semestre de 2018 ${ }^{7}$. Trataremos de questões metodológicas e, brevemente, de formação de professores, de maneira a contextualizar o curso e seu momento de ensino.

Ministrado ao longo de oito semanas consecutivas, o curso abordou aspectos de produção escrita em língua inglesa e tratou, com mais ênfase, da produção de ensaios. Devemos salientar que o curso em questão, além de desenvolvido em EAD, foi idealizado e promovido entre a parceria/financiamento de uma empresa privada com uma universidade pública do interior paulista e, por isso, seu público-alvo fazia parte de um dos campus da instituição de ensino superior.

Esse curso foi ministrado de maneira extracurricular, gratuito, e com direito a certificação com carga horária cursada (com mínimo de $75 \%$ de presença e média final 6). $\mathrm{O}$ curso tinha como carga horária total 32 horas de trabalho, 16 delas eram síncronas e as horas restantes eram para atividades assíncronas na plataforma Moodle (Modular Object-oriented Dynamic Learning Environment), em que os alunos podiam tirar dúvidas e entregar as produções textuais para serem corrigidas pela professora.

Ainda sobre esse contexto de realização do curso e ensino a distância, utilizamo-nos de programa de videoconferência $\mathrm{Zoom}^{8}$, que permitia a separação de alunos em pequenos grupos de modo que a realização de discussões foi possível, corroborando, assim, com a abordagem comunicativa adotada pela professora.

${ }^{7} \mathrm{Cf}$. Quadro 1 para resumo de informações principais a esse respeito.

${ }^{8} \mathrm{O}$ Zoom é um aplicativo de webconferência com interface mais estável. Permite que o usuário acesse uma reunião por meio de um link gerado especificamente para tal, de modo que, em nosso contexto, o único que precisa ter uma conta ativa no aplicativo é o professor (anfitrião). O aplicativo também permite que as aulas sejam gravadas e exportadas, assim, os alunos que faltaram podem ter acesso posterior ao conteúdo. A versão usada no momento do curso é paga, apesar disso o aplicativo pode ser baixado gratuitamente. Maiores informações sobre o aplicativo podem ser encontradasno link a seguir. Disponível em: https://zoom.us/. Acesso em: 09 jun. 2019. 
Como o curso tinha por objetivo o desenvolvimento das habilidades de escrita em língua estrangeira, em especial ao que dizia respeito a ensaios, a professora optou por estruturar cada uma das aulas de modo a abordar um aspecto principal em relação ao processo de escrita: a fase de pré-escrita, com atividades para desenvolver argumentos e elementos textuais individuais (parágrafos, pontuação, entre outros); a produção do rascunho dividida por tipos de parágrafos e suas funções no texto; e a revisão e edição textual, com foco específico em formatação em diversas normas acadêmicas (ABNT, MLA, APA).

Conforme foi analisado pelos questionários de análise de necessidades respondidos pelos alunos antes do início do curso, muitos acreditavam que precisavam melhorar mais de uma das habilidades de aprendizagem de língua inglesa (a saber: listening, speaking e reading, writing), mas decidiram se inscrever para um curso de produção escrita porque se inseriram em meio acadêmico e era desta habilidade que tinha maior demanda.

Levando em conta essa necessidade dos alunos, de explorar as quatro habilidades da língua inglesa, o planejamento da professora, embora privilegiasse o uso da habilidade escrita e abordasse os aspectos formais dessa prática, buscou fomentar, também, o desenvolvimento das outras três habilidades ao longo do curso.

Como já tratamos em itens anteriores, a produção escrita - assim como a leitura, produção oral e recepção oral - é apenas uma das habilidades passíveis de ser abordada em cursos de IFA. Sobre isso, a professora salienta que durante a realização da primeira aula, vários alunos mostraram-se surpresos pelas aulas serem, de fato, ministradas em inglês, mesmo tendo como foco a escrita.

Além disso, salientamos que todo o curso foi desenvolvido a distância e, ao total, teve 9 alunos (de 20 iniciais) concluintes. Isso nos mostra que, conforme apontam Harker e Koutsantoni (2005), em se tratando de cursos a distância, ainda temos de superar o desafio da evasão de alunos. Em parte, acreditamos que a evasão se deve ao fato da cultura de aprender ${ }^{9}$ (ALMEIDA FILHO, 1993) desses alunos e, embora não gostaríamos que assim o fosse, acreditamos que a cultura de aprender brasileira tem como base o ensino presencial.

Em geral, notamos que, conforme já salientavam Harker e Koutsantoni (2005), o rendimento dos alunos foi satisfatório e teve mais relação com a própria dedicação ao curso do que com o formato em que ele foi ministrado. Ao longo das oito semanas de aulas síncronas pelo programa de videoconferência, os alunos também contavam com o apoio da professora

${ }^{9}$ Almeida Filho (1993) salienta que cultura de aprender trata-se "maneiras de estudar e de se preparar para o uso da língua-alvo consideradas como 'normais' pelo aluno, [...] transmitidas como tradição, através do tempo, de uma forma naturalizada [...], e implícita” (p. 13). 
através de e-mail e mensagens instantâneas pelo WhatsApp, podendo contatá-la sempre que precisassem.

De modo geral, os contatos ocorreram para tratar de prazos/extensões de entrega de atividades e dúvidas a respeito delas. Dúvidas sobre conteúdos, gramática e escrita eram, principalmente, tratadas durante as aulas síncronas, em que todos os alunos tinham abertura para fazê-lo (mesmo que também o tivessem por essas formas de contato). Além desse contato, os alunos também contavam com a plataforma Moodle para o download de materiais de aula (preparados pela professora, conforme temos em IFA), upload de tarefas, avaliações e questionários, e também contavam com espaço para postagem e discussão de dúvidas.

Como a professora já havia ministrado outro curso de IFA com a mesma temática da produção de ensaios, mas em um contexto distinto (presencial e para alunos de Letras com habilitação em inglês), o cronograma foi embasado, em parte, por sua experiência anterior (o que justifica nossa discussão sobre senso de plausibilidade) e pelas respostas dos alunos à análise de necessidades.

Dessa forma, os alunos estavam motivados a continuarem o curso. A professora observou que durante a realização do primeiro encontro síncrono, quase todos os 20 alunos inscritos compareceram, entretanto, já na segunda aula, vários haviam evadido porque a aula era ministrada em inglês e muitos dos alunos não conseguiam acompanhá-la. Embora para ingresso no curso fosse necessário um nível mínimo de B1 (segundo o Quadro Europeu Comum de Referências em Línguas, doravante $\mathrm{QECR}^{10}$ ), a professora notou que grande parte dos alunos encontravam-se em transição entre $\mathrm{A} 2 \rightarrow \mathrm{B} 1$ no momento de realização do curso, mesmo com a obtenção deste nível por meio de prova de nivelamento online, e que apenas um de seus concluintes realmente possuía B1.

No quadro abaixo, sistematizamos esta e outras questões expostas na sequência para facilitar a visualização e compreensão das informações apresentadas.

${ }^{10}$ Nesse artigo, não focaremos nas habilidades e competências necessárias para o desenvolvimento dos níveis propostos pelo QECR. Para mais informações a esse respeito, acesse: https://www.coe.int/en/web/languagepolicy/home (em inglês). 
Quadro 1 - Resumo de Informações sobre Curso de IFA EAD ${ }^{11}$

\begin{tabular}{|c|l|l|}
\hline TÓPICO & \multicolumn{1}{|c|}{ DADO } & \multicolumn{1}{|c|}{ DISCUSSÃO } \\
\hline CONTEXTO & EAD | IFA | Institucional & $\begin{array}{l}\text { Requisito: QECR: B1 } \\
\text { Real: QECR A2 } \rightarrow \text { B1 }\end{array}$ \\
\hline EVASÃO/RETENÇÃO & $\begin{array}{l}20 \text { alunos inscritos } \\
9 \text { alunos concluintes }\end{array}$ & $\begin{array}{l}\text { Evasão devido a não compreensão de LE, } \\
\text { choque de horários, não posse de aplicativo } \\
\text { de mensagens instantâneas, problemas em } \\
\text { letramento digital. }\end{array}$ \\
\hline RENDIMENTO & $\begin{array}{l}\text { obtiveram dendimento superior à } \\
\text { média 6 estabelecida (8 de } \\
\text { alunos). }\end{array}$ & $\begin{array}{l}\text { Conforme Harker e Koutsantoni (2005), o } \\
\text { rendimento dos alunos mostra-se similar a } \\
\text { comparação com os cursos realizados } \\
\text { presencialmente em outros contextos. }\end{array}$ \\
\hline
\end{tabular}

Fonte: elaborado pelas autoras

Em junção à essa crença (aulas ministradas em inglês em detrimento do português (língua estrangeira x língua materna)) e problemática dos alunos (a não-fluência necessária para o acompanhamento do curso), também notamos como especialmente latente a falta de letramento digital dos alunos. Embora, em sua maioria, pertencentes à geração dos nativos digitais (entre 18-25 anos), os alunos do curso tiveram algumas dúvidas em relação à utilização da plataforma Moodle (logo sanadas pelo costume de uso, já que as atividades e avaliações faziam com que acessassem a plataforma ao menos uma vez durante a semana) e ao programa de videoconferência utilizado nas aulas síncronas.

Os discentes, por meio do questionário de avaliação de curso final, também reclamaram de interrupções da aula por outros professores, uma vez que o aplicativo de videoconferência utilizado era compartilhado e disseram que "era falta de respeito" os outros professores não respeitarem o horário de aula. Como neste curso utilizávamos a versão paga do aplicativo, o email de acesso era compartilhado entre os diversos professores que usavam o Zoom em seu momento de aula. As aulas eram agendadas e compartilhadas em calendário específico interno, divulgado para os professores para que todos se preparassem para suas aulas e compartilhassem o link de acesso a elas com os alunos. A queixa do discente a respeito da interrupção da aula que ocorreu porque, por muitas vezes, outros professores acessavam a mesma conta utilizada pela professora para ministrar a aula e acabavam aparecendo na mesma tela de aula, de modo

${ }^{11}$ Todas as abreviações presentes no quadro já foram discutidas ao longo do artigo e podem ser encontradas por extenso. 
que a conta da professora ministrante ficava congelada momentaneamente, logo voltando a funcionar quando o outro professor saía da sala de aula virtual.

Os discentes também sugeriram que o material (especificamente as apresentações em PowerPoint) poderiam ser compartilhadas antes, e que ao invés de duplas as atividades podiam ser discutidas em grupo, já que assim teriam mais o que expor e discutir. Ainda, um dos discentes expôs em questionário de avaliação de curso que "esse curso deveria ser oferecido em vários momentos. Esse tipo de ação se torna a vida dos estudantes" (grifos nossos). É interessante notar que esse aluno em especial não especificou sua fala; criamos algumas hipóteses $^{12}$ em relação a ela: a) cursos de IFA ministrados em EAD; b) cursos de ensaios ministrados em EAD; e algumas proposições mais genéricas como c) cursos em EAD gratuitos; d) cursos de IFA gratuitos.

Em suma, a professora acredita que o problema principal da realização do curso foi a evasão. Como já abordamos, atribuímos essa evasão à cultura de aprender dos alunos brasileiros e relacionamos essa questão com o letramento digital, à questão de os alunos serem nativos ou imigrantes digitais. Especificamente tratando de abordagem de ensino, como já expusemos brevemente, não houve mudança do curso presencial para a modalidade EAD, sendo a abordagem comunicativa a utilizada pela professora. Em geral, as mesmas técnicas e ferramentas utilizadas pela professora no curso presencial também foram utilizadas no EAD durante a realização das aulas síncronas (debates, exposição de textos, discussões guiadas e livres, produções escritas guiadas, slides, áudios e vídeos, etc.); a única "limitação ${ }^{13}$ ” foi o nãouso de tarefas que exigiam o espaço físico e que poderiam propiciar a interação entre os alunos para a resolução de problemas (task-based learning).

\section{Considerações finais: encaminhamentos a respeito de IFA e EAD}

Como buscamos discutir nos itens anteriores, o trabalho do professor em sala de aula de LE, especificamente em contextos de IFA e EAD, é permeado por diversos fatores, entre eles temporais e contextuais, assim como pelas crenças e experiências do professor, pelos propósitos e objetivos de ensino, e pelo perfil dos aprendizes como discorremos ao longo deste artigo, mas não somente esses fatores.

\footnotetext{
${ }^{12}$ Por limitações espaciais, não pretendemos aprofundar esses assuntos.

${ }^{13} \mathrm{O}$ termo está entre aspas uma vez que consideramos essa mudança mais uma adequação ao uso de tecnologia do que limitação propriamente dita. 
Sabemos que, em alguma medida, este artigo apresenta limitações em suas discussões e que o recorte que utilizamos é apenas uma maneira de discorrer sobre os assuntos aqui apresentados. Salientamos, contudo, que, como esperamos ter discorrido ao longo das seções sobre abordagens e ensino de IFA, que cada contexto de ensino de língua estrangeira, seja ele ministrado em EAD, ou presencial, seja de língua "geral" ou para fins acadêmicos, cada um apresenta suas particularidades que devem ser bem analisadas pelo professor.

Para tanto, acreditamos que um dos principais tópicos a serem desenvolvidos em Linguística Aplicada, levando em conta tanto a formação inicial quanto a continuada dos professores, é a reflexão acerca do senso de plausibilidade do professor, especificamente para fins acadêmicos num contexto de aulas em ambiente online síncrono. Essa reflexão metodológica pode ser desenvolvida em parceria com uma sólida formação em ensino de línguas para fins acadêmicos (e suas técnicas), bem como o planejamento de cursos e a elaboração de material didático de IFA (como, por exemplo, a análise de necessidades) que se mostram instrumentos enriquecedores para os mais diversos contextos de atuação docente.

AGRADECIMENTOS: Ao Conselho Nacional de Desenvolvimento Científico e Tecnológico (CNPq), pelo fomento.

\section{REFERÊNCIAS}

ALMEIDA FILHO, J. C. P. de. Dimensões comunicativas no ensino de línguas. Campinas, SP: Pontes, 1993.

CAMPOS-GONELLA, C.O. A influência do material didático na motivação de aprendizes da língua inglesa em contexto de ensino público. 2007. 192 f. Dissertação (Mestrado em Ciências Humanas) - Universidade Federal de São Carlos, São Carlos, 2007

DA SILVA, V. F; ESTARNECK E. S. Motivação no ensino de língua inglesa: uma experiência de observação em uma escola pública. Revista Semioses, Rio de Janeiro. v. 01. n. 07, ago. 2010. Disponível em: http://apl.unisuam.edu.br/semioses/pdf/n7/n7_art_06.pdf. Acesso em: 30 jun. 2018.

DE CHAZAL, E. English for academic purposes. Oxford handbooks for language teachers. London: Oxford University Press, 2014.

DUDLEY-EVANS, T. Genre Analysis and ESP. ELR Journal, Birmingham (Reino Unido), n. $1,1987$.

DUQUEVIZ, B. C. Tecnologias digitais: sentidos atribuídos por adolescentes à aprendizagem de Língua Estrangeira. Orientadora: Regina Lucia Sucupira Pedroza. 2017. xiii, 
139 f. Tese (Doutorado em Processos de Desenvolvimento Humano e Saúde) - Universidade de Brasília, Brasília, 2017. Disponível em: https://repositorio.unb.br/handle/10482/23598. Acesso em: 30 jun. 2018.

GOMES, M. J. E-learning: reflexões em torno do conceito. Disponível em:

https://repositorium.sdum.uminho.pt/bitstream/1822/2896/1/06MariaGomes.pdf. Acesso em: 02 de out. de 2018.

HARKER, M.; KOUTSANTONI, D. Can it be as effective? Distance versus blended learning in a web-based EAP programme. ReCALL, v. 17, n. 02, p. 197-216, 2005.

HUTCHINSON, T.; WATERS, A. English for specific purposes. A learning-centred approach. Cambridge University Press, 1987.

KUMARAVADIVELU, B. Beyond methods: macrostrategies for language teaching. New Heaven, CT and London: Yale University Press, 2003.

LARSEN-FREEMAN, D. Techniques and principle language teaching. New York: Oxford University press, 2013.

LEFFA, V. J. Ensino de línguas: passado, presente e futuro. Revista de Estudos da Linguagem, Belo Horizonte, v. 20, n. 2, p. 389-411, jul./dez., 2012.

MILL, D. (org.) Dicionário crítico de educação e tecnologias e de educação à distância. Campinas, SP: Papirus, 2018. p. 198-214.

PRABHU, N. S. Second language pedagogy. Oxford: Oxford University Press, 1987.

PRABHU, N. S. There is no best method - Why? TESOL Quarterly, v. 24, p. 161-172, 1990.

PRABHU, N. S. Ideação e ideologia na pedagogia das línguas. Trabalhos em Linguística Aplicada, Campinas, v. 38, p. 59-67, 2001.

PESSÔA, A. R.; DUQUEVIZ, B. C. Professores de Línguas Estrangeiras e o uso de TICs. In: CONGRESSO BRASILEIRO DE LINGUÍSTICA APLICADA, 9., 2012, Rio de Janeiro.

Anais [...]. Rio de Janeiro: Universidade Federal do Rio de Janeiro, jul. 2011.

PRENSKY, M. Digital natives, digital immigrants. On the horizon, MCB University Press, v. 9, n. 5, p. 1-6, 2001.

SILVA, P. C. D.; SHITSUKA, R.; MORAIS, G. R. Estratégias de Ensino/Aprendizagem em Ambientes Virtuais: Estudo Comparativo do Ensino de Língua Estrangeira no Sistema EaD e Presencial. Revista Brasileira de Aprendizagem Aberta e a Distância (RBAAD) -ABED, v. 12, p. 12-25, 2013. Disponível em:

http://www.abed.org.br/revistacientifica/_Brazilian/2013/1A_Artigo_Rbaad_Portugues_2ed.p df Acesso em: 10 out. 2018.

XAVIER A. C. Letramento digital e ensino. 2002. Disponível em http://www.nehte.com.br/artigos/Letramento-Digital-Xavier.pdf Acesso em: 10 out. 2018. 


\section{Como referenciar este artigo}

DOTTI CAMPANATTI, A. H.; COSTA, T. D, KANEKO-MARQUES, S. M. Inglês para fins acadêmicos e o ensino a distância: pontos de contato e problemáticas. Rev. EntreLínguas, Araraquara, v. 6, n. 2, p. 340-356, jul./dez., 2020. e-ISSN: 2447-3529. DOI: https://doi.org/10.29051/el.v6i2.13499

Submetido em: $27 / 03 / 2020$

Revisões requeridas: $20 / 05 / 2020$

Aprovado em: 16/07/2020

Publicado em: 30/09/2020 